\title{
Sandwiched Kagomé Lattices in a Coordination Polymer based on Mixed-Valent Uranium
}

Volodymyr Smetana, ${ }^{\S}$ Steven P. Kelley, ${ }^{\star}$ Hanwen Pei, ${ }^{\S}$ Anja-Verena Mudring,,$^{\S}{ }^{\star}$ and Robin D. Rogers ${ }^{\S,+}, *$

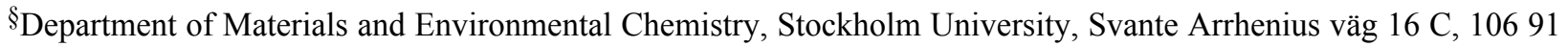
Stockholm, Sweden

†College of Arts \& Sciences, The University of Alabama, Tuscaloosa, AL, 35487

*E-mail: anja-verena.mudring@mmk.su.se; rdrogers@ua.edu

\section{Supplementary Information}

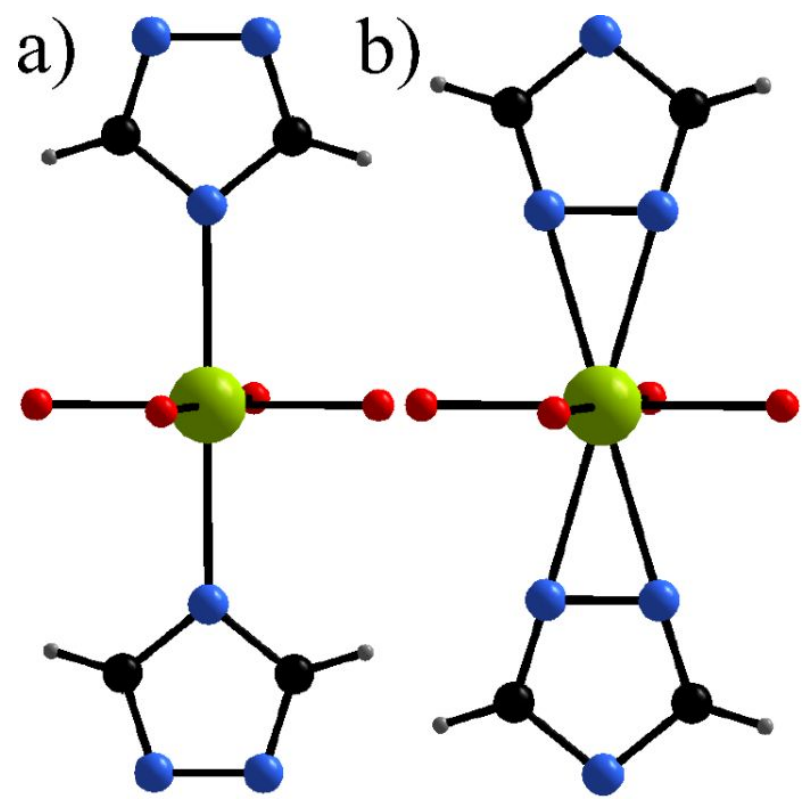

Figure S1. Possible coordination of $\mathrm{U}$ by Triaz. Red spheres corresponds to either monodentate $\mathrm{O}^{2-}$ or $\mathrm{H}_{2} \mathrm{O}$. a) corresponds to the coordination of $\mathrm{U} 2$, while $\mathrm{b}$ ) corresponds to the coordination of $\mathrm{U} 3$. 


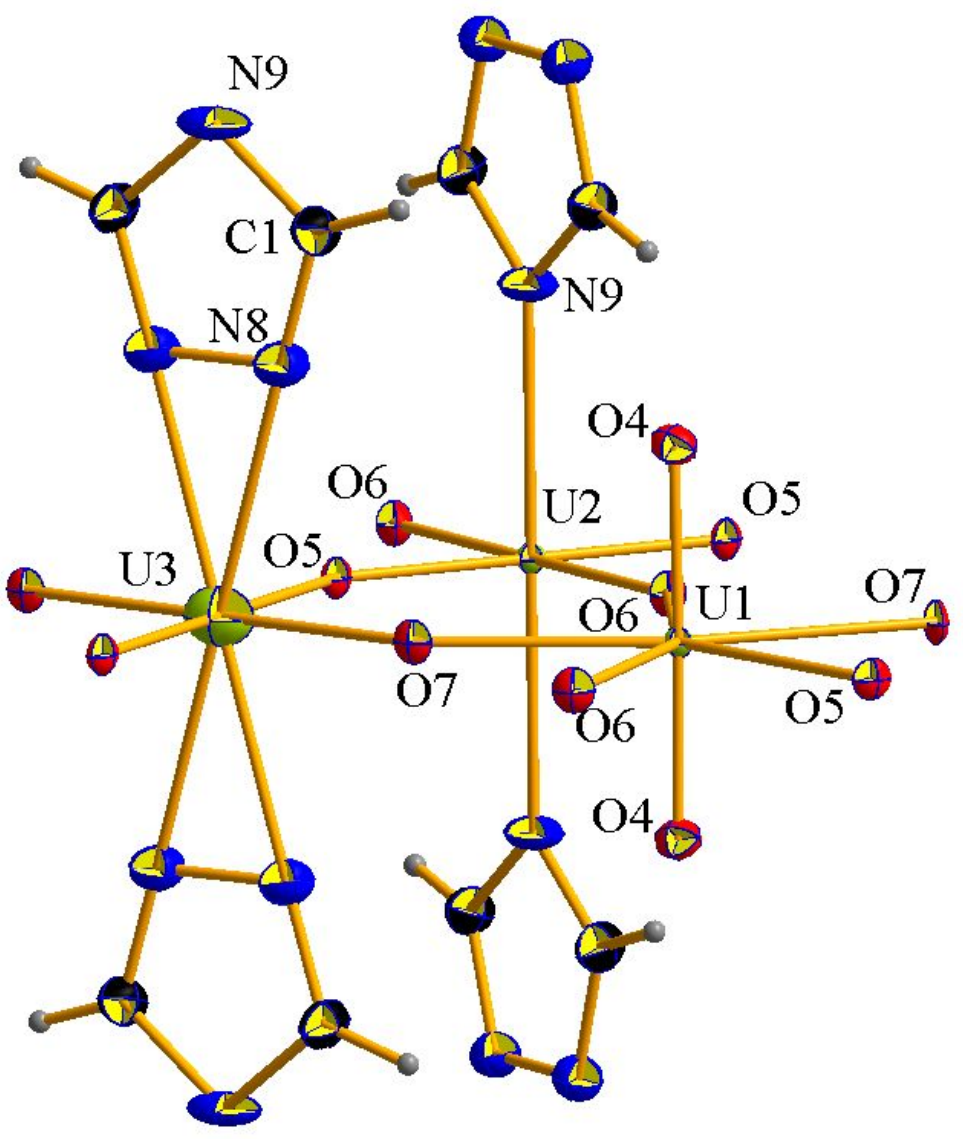

Figure S2. Ortep diagram of $\mathrm{U}^{\mathrm{V}} \mathrm{O}\left(\mathrm{U}^{\mathrm{VI}} \mathrm{O}_{2}\right)_{2}(\mathrm{OH})_{5}(\mathrm{Triaz})_{2}$. 
Table S1. Metal-ligand bond lengths $(\AA)$ and atom valences in $\left(\mathrm{UO}_{2}\right)_{2}\left[\mathrm{UO}_{4}(\mathrm{Triaz})_{2}\right](\mathrm{OH})_{2}$.

\begin{tabular}{lccccc}
\hline Bond & U1 & \multicolumn{3}{c}{ U2 } \\
\hline U-O1 & 1.773 & & & & \\
U-O2 & 2.496 & & & 1.855 & \\
U-O3 & 2.397 & & & 2.124 & \\
U-O3 & 2.327 & & & 2.124 & \\
U-O5 & 2.441 & & & 2.077 & \\
U-O5 & 2.330 & & & 2.077 & \\
U-N & & & & 2.442 & \\
\hline Site & U1 & U2 & U1* & $\Sigma$ & type \\
\hline O1 & 1.709 & 0 & & 1.709 & $\mathrm{O}^{2-}$ \\
O1 & 1.709 & 0 & & 1.709 & $\mathrm{O}^{2-}$ \\
O2 & 0.424 & 1.459 & & 1.613 & $\mathrm{O}^{2-}$ \\
O2 & - & 1.459 & & 1.613 & $\mathrm{O}^{2-}$ \\
O3 & 0.513 & & & 1.027 & $\mathrm{OH}^{-} / \mathrm{H}_{2} \mathrm{O}$ \\
O3 & 0.513 & & & 1.027 & $\mathrm{OH}^{-} / \mathrm{H}_{2} \mathrm{O}$ \\
O5 & 0.472 & 0.951 & 0.472 & 1.895 & $\mathrm{O}^{2-}$ \\
O5 & 0.584 & 0.951 & 0.584 & 2.119 & $\mathrm{O}^{2-}$ \\
$\mathrm{N}$ & 0 & 0.232 & & & $\mathrm{Triaz}^{2-}$ \\
$\mathrm{N}$ & 0 & 0.232 & & & Triaz \\
V & 5.924 & 5.283 & & & \\
\hline
\end{tabular}

